\title{
As relações jurídicas dos cônjuges
}

\author{
Lino de Morais Leme \\ (Catedrático de Direito Civil)
}

1. A Bíblia diz que a mulher é formada de uma costela do homem. Em seguida - Benedixit illis Deus et ait: crescite et multiplicamini et replete terram. De uma das costelas, diz Domat, para significar que ela e o homem formam um só todo, e que ela é dada ao homem como companheira e auxiliar.

Entre os povos antigos, vê-se que, na China, as mulheres vivem quase sempre encerradas. $\mathrm{Na}$ Índia, a mulher fica subordinada ao pai, ao marido, ao primogênito ou ao chefe da família, conforme a hipótese. Na Grécia, porém, já repontam as idéias de igualdade entre o homem e a mulher, como se vê na República, de Platão, em célebre diálogo entre Socrates e Glauco. Mas, como diz Voltaire, em seu Dicionário filosófico: "O verdadeiro mal não é a desigualdade: é a dependência".

Segundo o direito romano, a mulher, se alieni juris, ficava sujeita ao poder do pai ou do marido; se sui juris, em tutéla perpétua, propter sexus infirmitatem et propter forensium rerum ignoratium (Ulpiano, Cicero), situação que perdurou até à época post-clássica, quando foi suprimida a tutela mulierum, pela lei Cláudia.

2. Um retrato da situação da mulher, nos tempos antigos, se vê nas Ordenações, L. 5, Tit. 36, § 1..$^{\circ}$ que isentavam de pena aquele que castigasse "criado, discipulo, sua mulher e seu filho", e no provérbio provençal — Li fems non soun gèns - "Les femmes ne sont personne". Essa orientação resultou das tradições do direito romano. 
Também entre os anglo-saxões, na Idade-Média, a mulher era considerada menor, tendo o marido poderes absolutos sobre os bens.

3. Os poderes de que era dotado o senhor feudal e as guerras concorreram para manter a mulher nessa situação de inferioridade. Nos países nórdicos e anglo-saxões, que não conheceram o regime feudal e invasões repetidas, embora tivessem feito guerras externas, vê-se como a mulher adquiriu consideração. A fórmula de esponsais solenes, entre os nórdicos, assemelhava-se à do casamento anglo-saxão, que é de origem germânica: "A ti (a noiva), a honra e os direitos de esposa; a ti, as chaves da casa, a metade de meu leito, o terço do que possúo e do que adquirirmos juntos". Mas, fóra essas atenuações, perdura, na Idade-Média, a hostilidade contra os direitos sucessórios da mulher, representada pela manutenção do regime dotal, na Italia e em parte da França, nos moldes romanos, e pela concessão de um direito de usufruto sobre a metade ou a terça parte dos imóveis do marido, sendo a regra que, não havendo filhos, os bens de cada cônjuge voltariam para a família da qual tinham vindo - Paterna paternis, materna maternis. A mulher continuava a ser considerada uma menor, sob a tutela do marido, que era o senhor e o chefe de casal, tendo o gôso dos bens próprios da mulher, a qual não podia fazer contrato nem estar em Juízo, sem autorização.

4. Na Inglaterra, embora atenuada pela influência da Igreja Cristã e pelo abrandamento dos costumes, após as invasões dos bảrbaros, ainda no sec. XVI dizia Bacon: “A lei não permite senão uma vontade única entre os esposos, a do marido, que é o mais capaz de prover às necessidades da família, e dirigi-la. O Marido tem, por lei, poder e domínio sobre sua mulher. Ele póde constrange-la a ficar no limite de seus deveres, e batê-la, contanto que o faça sem crueldade, nem violência". 
5. Todos sabem o que foi a Idade-Média, na qual, todavia, apareceram alguns vultos notáveis, como o do grande Santo Tomaz de Aquino - o autor do hino ao Santissimo Sacramento - S. Boaventura, S. Bernardo, e em que foi escrito esse livro incomparável, que é a Imitação de Cristo.

Com a quéda desse regime, sob a influência do Cristianismo, era natural que melhorasse a condição da mulher. Mas também na ordem social vê-se que reina analogamente a conhecida lei de Lavoisier - Natura non facit saltus.

Foi assim que, embora desaparecendo, na maior parte dos países, a tutéla perpétua da mulher, com o estabelecerse que a mulher celibatária ou viuva tinha a mesma capacidade que o homem, contudo as legislações vieram a consignar o poder marital e o "dever de obediência", seguindo o art. 213 do Código Civil francês. "Poder marital - define o Código do Chile, art. 132 - é o conjunto de direitos que as leis concedem ao marido, sobre a pessôa e os bens da mulher". Desse poder decorria a obrigação de a mulher habitar com o marido e de segui-lo para onde ele entendesse de residir, sem estabelecer-se reciprocamente que o marido é obrigado a habitar em companhia da mulher. A jurisprudência fírancesa admitia o recurso à força pública, para a mulher ser obrigada a acompanhar o marido, orientação seguida pela lei argentina sobre o casamento, art. 53. Essa obrigação da mulher é consagrada ainda em Códigos dos mais recentes, como os do México (art. 163), o da Itália (art. 144), sendo que o primeiro acompanha o Código espanhol, que permite ao Poder Judiciário eximir a mulher dessa obrigação.

O Código do Perú, que é de 1936, seguindo o Cód. da Alemanha (art. 1.354), diz que a mulher não está obrigada a aceitar a fixação do domicilio conjugal, quando a decisão do marido constitúa um abuso de direito (art. 163). O Código português (art. 1.186) e o do México isentam a mulher da abrigação de acompanhar o marido, quando ele se mude para o estrangeiro, especificando o segundo - 
“sendo em serviço da pátria", bem assim quando se estabeleça em lugar insalubre ou indecoroso (art. 163).

Pelo poder marital, a mulher é equiparada ao menor e deve obediência ao marido. Esse dever de obediência, porém foi suprimido da maior parte das legislações - Código Civil da Alemanha (art. 1.354), da Suiça (art. 160), do México (art. 167), do Perú, da Venezuéla, da Dinamarca, da Suécia, da Noruéga, da Rússia; na Itália, pela lei de 1919, art. 131; na França, pelas leis de 1938 e 1942; no direito inglês e no americano. Mas ainda subsiste no Código Civil da Espanha (art. 57), do Chile (art. 31), do Uruguai (art. 128), de Portugal (art. 1.185), de Cuba (art. 57).

6. A tendência, porém, é para assegurar à mulher uma situação de igualdade com o marido. A lei potuguesa n. ${ }^{\circ}$ 1, de 25-XII-1910, estabelece: “A sociedade conjugal baseia-se na liberdade e na igualdade." O Código mexicano de 1928 (art. 167) dispõe que o marido e a mulher têm, no lar, autoridade e consideração iguais; no caso de divergência, não sendo possível acôrdo, decide o juiz. $O$ Código do Perú, de 1936 (art. 161), diz que o marido dirige (não emprega o vocábulo "chefia") a sociedade conjugal; que a mulher deve ao marido ajuda e conselho, e que ela tem o direito e o dever de atender pessoalmente ao lar. O Código venezuelano de 1942 (art. 140) estabelece que o marido decide quanto aos assuntos de vida econômica.

A Constituição de Cuba (1940) concedeu plena capacidade à mulher casada. Limitaram-se a abolir-lhe a incapacidade as legislações da Rumânia (1932), da Austria (1934), da Hungria, da Turquia, que foram precedidas pelas dos países nórdicos, da Inglaterra, dos Estados Unidos (aí quasi todos os Estados concedem à mulher plena capacidade jurídica), da Rússia, que estabelecem a igualdade jurídica entre o marido e a mulher.

Tão arraigada está a idéia da igualdade jurídica entre o homem e a mulher, que a Nova Conferência Interna- 
cional Americana, reunida em Bogotá, em 1948, aprovou a Resolução n. XX da 8. ${ }^{a}$ Conferência Internacional Americana, a saber" - que a mulher tem direito igual ao homem, na ordem civil; e, figurando esse principio na Carta das Nações Unidas, resolveu: Os Estados Americanos convêm em outorgar à mulher os mesmos direitos civis de que gosa o homem". Estiveram ai representados os seguintes países americanos - Honduras, Guatemala, Chile, Uruguai, Cuba, República Dominicana, Bolívia, Perú, Nicarágua, México, Panamá, S. Salvador, Paraguai, Costa Rica, Equador, Brasil, Haiti, Argentina e Colômbia.

7. Outra cousa é a simples igualdade dos sexos (Constituição alemã, de 1919, art. 119; Constituição espanhola (art. 43). A nossa Lei Magna estabelece que "todos são iguais perante a lei" (art. 141, n. I), e a proibição de diferença de salário por motivo de sexo (art. 157, n. II). O último artigo citado mostra que o princípio do art. 141, n. I, não tem o alcance que Pontes de Miranda lhe pretendeu emprestar.

8. Concedida a igualdade jurídica à mulher, surgem dois problemas capitais: o da chefia (ou direção) da sociedade conjugal, e o da administração e alienação dos bens. Essa chefia é geralmente conferida ao marido Código Civil da Itália (art. 144), do Perú (art. 161), da Alemanha (art. 1.354), da Suiça (art. 162), da Turquia, da Grécia, da Venezuéla, da Rússia, para sòmente citar os de 1900 para cá. O Código do México pretendeu estabelecer a direção conjunta, ao dizer que o marido e a mulher terão, no lar, autoridade e consideração iguais.

Pelo dierito canônico, do matrimônio válido se origina entre os cônjuges: a) um vínculo que é, por sua natureza, perpétuo e exclusivo; o matrimonio cristão confere, além disso, a graça aos cônjuges que não lhe põem óbice (1) ; b) uma comunhão de vida entre os cônjuges - tori, men-

(1) Código de Direito Canônico, ‘c. 1.110. 
sae et habitationis, nisi justa causa non excuset ${ }^{(2)}$; c) poder marital; d) participação da mulher em o nome, estado, dignidade e privilégios do marido, a não ser que por direito especial se haja estabelecido diferentemente ${ }^{(3)}$; e) os mesmos direitos e obrigações no que se refere aos atos próprios da vida conjugal (4).

A respeito, o S. Padre, Papa Pio XII, em alocução de 1942, salienta a necessidade essencial, em toda a sociedade, de que exista um chefe (na sociedade conjugal é o marido), que jamais poderá desconhecer sua igualdade substancial com o seu cônjuge, e que assim desenvolve: a) igualdade substancial entre ambos os cônjuges, ideológicamente fundada no conceito cristão da pessôa, e vitalmente praticada graças ao domínio do egoismo e ao amor conjugal, título bastante para a tolerância das fraquezas; b) autoridade hierárquica do marido, e não domínio material, teleológicamente orientada para o bem comum familiar; c) deveres morais do marido, em razão dessa mesma autoridade, os quais lhe impõem a colaboração na educação dos filhos e na procura de recursos para atender aos encargos conjugais, além do auxílio necessário em certas tarefas do lar.

9. Não iremos indagar qual o melhor regime de bens, para a igualdade econômica entre o marido e a mulher, pois todos eles podem ser organizados por fórma a ser colimado esse objetivo. Assim, vamos passar em revista a situação dos cônjuges, nos vários regimes de bens.

No regime da comunhão universal, não póde um cônjuge dispôr dos bens imóveis, sem o consentimento do outro; assim, na Dinamarca, Noruéga, Islândia, Portugal, Brasil. De se notar que, em Portugal, a mulher não é obrigada pelas dívidas do marido, se não se obrigou juntamente com ele (art. 1.114), da mesma fórma que na Dinamarca,

(2) Idem, c. 1.128 .

(3) Idem, c. 1.112.

(4) Idem, c. 1.111. 
Noruéga e Islândia, em cujos países cada cônjuge administra os bens que levou para o casal, e póde deles dispôr, não sendo imoveis.

Nos países que adotam o regime da comunhão parcial de bens: a) em alguns, a mulher póde dispôr dos seus bens próprios (Código Civil do México (art. 172), do Perú (art. 178), da Venezuéla (art. 154 e 170 - aí até dos bens comuns, que administra); b) noutros, não póde (Código Civil da Espanha (art. 61), do Uruguai (art. 1.976), do Chile (art. 175), enquanto que o marido o póde fazer, não se tratando de bens da mulher (Código Civil francês. (art. 1.421 e 1.421), espanhol (art. 59), chileno (art. 1.750), uruguáio (art. 1.971). o Código chileno diz - "O marido é o dono dos bens sociais".

Na Suiça, onde o regime legal é o da união de bens, o marido póde dispôr dos bens comuns, sem consentimento da mulher, o qual se presume em favor de terceiros (art. 166 e 200). Na Alemanha, o regime é o da administração e usufruto, pelo marido, dos bens da mulher, e esta não póde deles dispôr, sem consentimento do marido (arts. 1.363 e 1.395). Quando adotado o regime da comunhão, o marido administra, e esses bens respondem pelas obrigações do marido, e não pelas da mulher, contraídas após a comunhão (arts. 1.437, 1.443, 1.459 e 1.462).

Na Suécia, na Finlândia e na Rumânia, vigora o regime da separação de bens ${ }^{(5)}$; cada cônjuge administra os seus bens, mas a alienação de imóveis depende do consentimento de ambos os cônjuges. Na Inglaterra, onde igualmente vigora o regime da separação de bens, a liberdade da mulher é restringida pelos marriage settlements e pelos trusts. Por esta instituição, o patrimônio dela é confiado a trustees (mandatários de confiança, homens da lei, parentes próximos, ban-

(5) Na Suécia e na Finlândia, o regime é o da separação em vida, e união, pela morte. Cada cônjuge responde pelas dividas que contrair. 
cos, etc.). O trust torna indisponíveis os bens da mulher, protegendo-a contra as dissipações do marido e da própria mulher. Dá o mesmo resultado que o regime dotal.

10. Ha um direito que é geralmente reconhecido: o de a mulher dispôr do produto de seu trabalho (lei francesa de 3.VII.1907, completada pela de 8.VI.1923); Cód. alemão (arts. 1.365 - 1.367); Cód. suiço (arts. 191 e 192); lei inglesa de 1870; lei suéca de 11.XII.1874; lei dinamarquesa de 7.V.1880; lei norueguesa de 29.VI.1888; lei belga de 1900; lei polonesa de 1921; lei turca de 1926; Cód. peruano, (art. 207). No Chile, a mulher tem apenas o direito de administrar (Cód. art. 1.521).

11. Reconhecida ao marido a chefia ou a direção da sociedade conjugal, competindo-lhe a representação da familia, ou a da mulher, a regra é que o poder de a mulher contratar fica restringido à hipótese de ela exercer profissão e, fóra desse caso, apenas com relação às necessidades domésticas e aos bens que administra e que pode alienar. Os sistemas a respeito, são os seguintes :

I. Cada cônjuge administra os seus bens e póde deles dispôr (Dinamarca, Suiçá, Noruéga (não sendo imóveis), Venezuéla (Cód. Civil, art. 170).

II. Sòmente o marido póde dispôr dos bens comuns (Cód. francês e belga, arts. 1.421 e 1.445; Cód. espanhol e cubano, art. 59; Cód. suiço, arts. 166 e 200; Cód. chileno, art. 1.750; Cód. uruguaio art. 1.971). O Cód. italiano exige o consentimento da mulher (arts. 217 e 220).

III. Em relaçâo aos bens próprios da mulher;

a) póde ela deles dispôr, independentemente de consentimento do marido: Cód. do México (art. 172), do Perú (art. 172), da Venezuéla (art. 154);

b) não póde ela dispôr: Cód. francês (art. 217), espanhol (art. 61), chileno (art. 175), uruguáio (art. 1.976). 
IV. Em algumas legislações, a mulher não póde nem adquirir sem consentimento do marido: Cód. francês (art. 217), espanhol (art. 60), chileno (art. 1.752).

V. Na Alemanha, a capacidade não é modificada pelo casamento, mas certos regimes restringem o direito de dispôr.

12. Quanto aos contratos entre cônjuges:

a) as doações eram proibidas no antigo direito romano, afim de que o amor recíproco não fosse causa para que eles se despojassem de seus bens, em doações excessivas (Digesto. 24-1, de donat. inter virum et uxorem). Depois foram admitidas, embora continuassem a observar esse princípio. Mas a regra não se aplicava ao casamento sine manu, em que a mulher não ficava sob o poder do marido.

Nas legislações estrangeiras, vê-se o Cód. Civil uruguáio (art. 1.656) declarar nulas as doações entre cônjuges, durante o casamento. O Cód. português (arts. 1.178 e 1.183) permite-as, contanto que não sejam no mesmo e único ato, mas as declara revogáveis livremente. O Cód. italiano (art. 784) proibe essa doações, salvo as de acôrdo com os usos. No México marido e mulher precisam de autorização para contratar um com o outro (art. 174). Na Venezuéla, não pode haver contrato de compra e venda entre os cônjuges (1.481).

No Brasil, o Projeto Clovis silenciava a respeito. A Comissão Revisora incluiu dois artigos, permitindo-as, mas foram suprimidos. A orientação vem do parecer da Comissão Especial: "Não se proibem as doações entre cônjuges, desde que pela natureza do regime matrimonial forem possiveis".

No regime da comunhão universal de bens ,essas doações são impossiveis, porque importariam em permitir alterações no regime de bens, que é irrevogável (art. 250). 
No regime da comunhão parcial de bens, é impossivel a doação quánto aos bens comuns, mas possivel quanto aos bens particulares alienaveis.

No regime de separação pura, é possivel quanto aos bens que sobejam dos encargos do casamento; no de separação limitada, é impossivel quanto aos bens comuns, e possivel quanto aos bens particulares.

No regime dotal, é possivel quanto aos bens particulares; o dote é inalienavel (art. 293).

b) Quanto á compra e venda:

— O Cód. francês (art. 1.595) enumera os casos em que a mesma é possivel.

— O Cód. espanhol admite-a apenas no regime de separação de bens, ou quando tiver havido separação judicial dos mesmos (arts. 1.458).

- O Cód. suiço admite todos os atos jurídicos, entre esposos, com as reservas que indica (art. 177).

$\longrightarrow \mathrm{O}$ Cód. mexicano também reconhece à mulher capacidade para contratar com o marido (art. 174); mas a compra e venda, só no regime de separação (art. 176).

- O Cód. do Perú estabelece que a mulher póde contratar e dispôr de seus bens, sem outras limitações senão as decorrentes do regime legal (art. 172).

- O Cód. da Venezuéla veda entre marido e mulher (art. 1.481).

- O Cód. português também, exceto achando-se separados de pessôas e bens (art. 1.564).

Em conclusão: em regra não se admite o contrato exceto no regime de separação de bens.

13. Sôbre a condição da mulher, de se observar que:

a) na Inglaterra, a mulher póde estar em juizo, agindo como a mulher não casada; mas a condenação recai apenas sobre os bens, não sobre a pessôa dela; 
b) nos Estados Unidos, é mais ou menos como na Inglaterra. Não ha o dever de obediência;

c) no direito escandinavo, a mulher é igual aø marido, mas ha limitações decorrentes da associação conjugal, e é a mulher responsável solidariamente com o marido, por dívidas para as necessidades do lar;

d) em Portugal, a sociedade conjugal baseia-se na liberdade e na igualdade ${ }^{(6)}$;

e) em diversos paises ha o dever de obediência ao marido. Assim na Espanha, Chile, Uruguai, Argentina, Cuba. Na França foi suprimida pela lei de 18.11.1938;

f) na França, a mulher não póde alienar, sem consentimento do marido (7); ele póde, sem outorga uxória (8); a mulher póde contratar, se o casamento for sem contrato; a mulher póde dispôr dos bens dotais adquiridos, sem licença do marido, se tiver mais de 45 anos; a mulher póde estar em juizo e contratar, se condenado o: marido por abandono de familia;

g) na Alemanha, a capacidade da mulher não é modificada pelo casamento, mas certos regimes restringem o direito de dispôr; e póde a mulher exercer profissão;

h) no Perú, o marido dirige e representa a sociedade conjugal. Ele fixa o domicilio da família, mas a mulher não está obrigada a aceitar a decisão, quando constitúa um abuso de direito ${ }^{(9)}$;

i) no México, marido e mulher pódem dispôr de seus bens próprios; mas, se menores, é necessária autorização judicial. A mulher póde exercer profissão, mas o marido póde opôr-se a esse direito, desde que proveja às necessidade do lar, e funde a oposição em causas graves e justificadas. Eecessária autorização judicial para a mulher se obrigar solidariamente com o marido, e ela precisa de au-

(6) Lei n. 1, de 25.12.1910, art. 39.

(7) Código Civil, art. 217.

(8) Idem, art. 1.421.

(9) C. C., arts. 162, 163. 
torização judicial para contratar com o marido, exceto por mandato ${ }^{(10)}$;

j) na Rússia, não são estabelecidos deveres reciprocos entre os cônjuges; o exercicio de profissão, pela mulher, é livre; a coabitação não é obrigatória; havendo mudança de domicílio, a mulher não é obrigada a seguir o marido; a família se baseia na filiação;

k) em Cuba, a Constituição de 1940 deu à mulher plena capacidade civil;

1) na India, a mulher deve obediência ao pai, ou ao marido, ao primogênito, ou ao chefe da família;

m) na Itália, o marido é o chefe da família; a mulher segue a sua condição civil, toma-lhe o nome e é obrigada a acompanhá-lo (12);

n) na Argentina, a mulher póde exercer profissão, fazer parte de sociedade, administrar e dispôr, a titulo oneroso, de seus bens próprios, ser tutora, curadora, etc. (13);

o) no direito mulçumano, havendo mais de uma mulher, cada uma tem direito a uma habitação separada;

p) na Venezuéla, os cônjuges são obrigados a viver juntos, guardar fidelidade, prestar-se auxilio mutuo. $\mathrm{O}$ marido deve proteção à mulher, e cabe-lhe decidir quanto aos assuntos da vida conjugal comum. O marido administra os bens comuns, e cada cônjuge os seus bens próprios, e póde dispôr a título oneroso ${ }^{(14)}$;

14. Deu-se o direito de voto à mulher: na Finlândia, em 1906; na Noruéga, em 1907; na Alemanha, em 1919; na Inglaterra, em 1929. Neste último pais, de 29 milhões de eleitores, ha alguns anos, 15 milhões eram mulheres.

(10) C. C., arts. 169, 170, 174, 175.

(11) C. C., art. 144.

(12) Lei n.o 11.537, de 22.9.1926.

(14) C. C., arts. 137, 139, 140, 154, 170. 
15. Na vida social, vemos a mulher nas escolas, nas industrias, no comércio, desempenhando um papel, na vida econômica, que era antes desempenhada pelos homens.

Sem o valor e a atividade das mulheres, não se teria ganho a guerra, disse Lloyd George, a propósito da primeira grande guerra. E de W. Wilson são os seguintes conceitos - Para que a União tenha podido lançar todas as suas forças materiais no conflito mundial, foi mister a mobilização voluntária das mulheres.

Mas, se à mulher se reconhece capacidade política e se deve reconhecer capacidade civil, contudo tem esta de sofrer as restrições decorrentes da existência da sociedade conjugal.

Certamente que ao marido deve ser reconhecido o direito de fixar o domicilio da família, salvo à mulher o direito de não acatar a determinação do marido, em caso de abuso de direito. $\mathrm{E}$ também ao marido deve competir o direito de autorizar a profissão da mulher, com suprimento judicial, no caso de oposição injustificada.

Deve a mulher ter o direito de administrar livremente e dispôr de seus bens próprios. Quanto aos bens comuns, deve a alienação deles ser feita mediante acôrdo dos cônjuges, se imóveis.

E devem permitir-se os contratos, inclusive de compra e venda, entre os cônjuges, quando o regime matrimonial o permita. 